\title{
A PROCESS MODEL RECOGNISING PRIOR LEARNING OF INFORMAL SECTOR MOTOR MECHANICS
}

\author{
C. J. Jordaan* \\ e-mail: jordaancj@tut.ac.za
}

\section{A. Bezuidenhout}

Department of Human Resource Management

University of South Africa

Pretoria, South Africa

e-mail: bezuia@unisa.ac.za

\section{Schultz*}

e-mail: SchultzCM@tut.ac.za

*Department People Management and Development

Tshwane University of Technology

Pretoria, South Africa

\section{ABSTRACT}

The informal sector serves as a reservoir of skilled unqualified individuals who learned and practice the motor mechanic trade outside the formal sector. This article reports on a process model for recognition of prior learning of informal sector motor mechanics and to integrate them into recognised sector training and ultimately formal employment. Formal sector motor mechanic training does not acknowledge non-formal learning of the informal sector. The process model identifies specific entry points into formal sector training. The study was exploratory in nature with a qualitative research design applied. Semi-structured interviews through a purposive snowball sample technique were used. The data were analysed utilising the ATLAS.ti 7.0 Program. The findings conceptualise a process model, backed by a process of gap training, to recognise the prior learning of the informal sector motor mechanic. This research could engage SETAs in the funding of training of informal practising motor mechanics.

Keywords: employable skills, reservoir, focused RPL, gap training and non-formal learning

\section{INTRODUCTION}

South Africa has a large pool of experienced and semi-skilled individuals working in the informal sector who have learnt and practised artisan trades informally and are ready for probable incorporation into the formal sector. (F. Prinsloo 2011 pers. comm.) The recovery of this untapped pool of skills could alleviate the shortage of artisan trades reported in the South 
African master skills inventory list. The current skills inventory report does not consider nonformal training and development or skills acquired in the informal sector (F. Prinsloo 2011 pers. comm.). Akoojee $(2011,108)$ emphasises that the absence of a lively apprenticeship recordkeeping system results in poor deployment of national human resources and is likely to influence the future rollout of the economic growth path, as far as it pertains to training and development of artisans in South Africa.

The need for expanding apprenticeship training to address the shortage of artisans has been attempted in several countries for example the United States of America (USA), the United Kingdom (UK), France and Norway, with varying degrees of success. Akoojee $(2011,108)$ maintains that if the South African apprenticeship system is to be revived, significant institutional and governmental support in the form of incentives or encouragement for employers is necessary. By implication, the need to progressively integrate the informally practising artisan into the formal sector of South Africa is thus also supported. (F. Prinsloo 2011 pers. comm.).

\section{LITERATURE REVIEW}

According to Esterhuisen (2012), the automotive industry recognises and supports the range of initiatives (National Growth Path, the National Skills Development System, the Skills Accord and the Industrial Policy Action Plan II) taken by the South African government to address the coordination of skills shortage problems pertaining to artisan trades. Esterhuisen (2012) explains that the automotive industry in South Africa accounts for 6.17 per cent of the gross domestic product (GDP) and employs 370611 people in 133 separate employment categories. The number of potential apprenticeship workplace opportunities is diminishing annually, compared to the number of vehicles produced and sold. The projection is that, by 2020, more than a million vehicles will be sold annually. Businesses invest large amounts of money (at R300 000.00 per apprentice) in the development and implementation of the motor mechanic apprentice programme (DHET 2013, 8). According to Esterhuisen (2012), employers in the automotive industry are setting smaller budgets with fewer employment opportunities for potential apprentice intakes.

The Amalgamated Motor Holdings (AMH 2012), reported, that the automotive industry had a minimum demand for 12249 learners in 17 motor mechanic trade areas. Only 1577 learners committed themselves, of which 1025 finally registered. In addition, the Automotive Production and Development Programme set targets to increase vehicle production, thereby effectively doubling the need for qualified motor mechanics (Esterhuisen 2012). 
In South Africa, the artisan who operates in the formal sector is accounted for by means of the Sector Education and Training Authorities (SETAs) and different Sectoral Skills Plans (SSPs). According to Botha, Kiley, Truman and Tshilongamulenzhe (2012, 609), an SSP is a description of a specific sector that refers to the current education and training happening in that sector. Botha et al. (2012, 609), however, report that SETAs and SSPs do not consider artisans who operate in the informal sector. Rasool and Botha (2011, 3), agree that poor labour market reporting models and old fashioned occupational forecasting systems amplify skills shortages in various artisan trades.

The Manufacturing, Engineering and Related Services Sector Education and Training Authority (MerSETA) is responsible for collecting data on training and development of the manufacturing, engineering and related sectors which include the automotive sector in South Africa. MerSETA $(2013,14)$ reports an increasing shortage of skilled technical motor mechanics in the South African automotive environment to act as mentors to guide apprentices. There is a lack of motivation and commitment among apprentices. A lack of discipline through poor time-keeping, low attendance in general and non-willingness to learn is reported (MerSETA 2013, 36).

The Institute of Motor Industry (IMI 2012) refers to the fast pace of development of new vehicle technology that creates a constant demand for advanced technical skills. Areas such as vehicle production and design, general repairs, body restoration and refinishing, airconditioning and electrical systems are becoming progressively multifaceted, demanding exceptional technical skills in a range of modern disciplines, using advanced specialist equipment.

Based on the above, it can be argued that motor mechanics who operate in the informal sector would not necessarily keep up with the latest technological advancements in the respective automotive fields (new electronic systems, low carbon emission engines and turbocharged engines). It is thus possible that they will lack specific training, development and experience in technologically advanced areas and thus need to be linked to formal sector training. (F. Prinsloo 2011 pers. comm.).

\section{Recognition of prior learning (RPL)}

Bolton (2011, 28) refers to RPL as the assessment of a learner's preceding learning and experience, regardless of how these were acquired, against the learning outcomes for an identified trade qualification. Breier $(2009,1)$, views the RPL system as a key principle of the National Qualifications Framework (NQF) and all qualifications are meant to be attained either 
as a whole or in different modules through the RPL process.

The DHET (DHET 2012, 8) sees RPL as vital importance in recognising the preceding learning of individuals who have become experienced and skilled in a specific technical sector over a number of years. Connellan $(2011,8)$, refers to an Organisation for Economic Cooperation and Development (OECD) report who defines recognition of prior learning as: “... the identification off learning acquired through work and other life experiences outside the formal education system ...”. Stuart $(2010,158)$ elaborates that the RPL system in South Africa is based on the need to provide access to learning for workers who have informal skills and knowledge that could be recognised formally, for example, the non-formal training of the informal motor mechanic.

Hamill and Sutherland $(1994,2)$ assert that RPL has two major purposes, namely to provide entry to a programme whose admission requirements are lacking and to exempt candidates from certain parts of a course for which they already have experience. Bowman et al. $(2003,5)$ propose that the accreditation of RPL should be founded on the belief that a person is regarded as skilled when industry or enterprise competency standards are achieved.

Andersson, Fefes and Ahn $(2004,3)$ contend that RPL models employ mainly two methods, namely portfolios of evidence and reliable summative tests. Castle and Attwood (2001, 7), state that a portfolio of evidence should have a self-reflective essay which could serve as an analytic tool for student placement and curriculum planning. Bowman et al. (2003, 6), posit that hard copies of portfolio of evidence are the most often used mode of RPL assessment despite their visible constraint of not being appropriate in some situations.

DHET (DHET 2012, 3) states that unionised workers and employers have to agree on the selection criteria for artisan trades to qualify for an RPL assessment, namely:

- A person who is not registered for a formal artisan learning programme.

- A person with five years or more working experience in an artisan trade, either at one employer or multiple employers or self-employed.

- People who have completed a self-assessment of their trade experience compared to the evidence stated in the RPL toolkit. This must be done with the support of RPL advisors, who confirm that the applicant have covered 80 per cent of the trade curriculum.

\section{RPL toolkits and advisors}

The DHET (DHET 2012, 5) has a detailed RPL toolkit guide that explains the evidence required for a RPL candidate to prove that he/she has the prerequisite knowledge and experience in a 
relevant artisan trade. According to DHET (DHET 2012, 6), compiling trade related evidence requires an administration skill that is seldom related with people working in a technical workplace such as artisan-related occupations. Therefore, a full-time RPL advisor should be appointed to administratively support persons applying for artisan RPL assessment. RPL advisors submit all portfolios of evidence to the National Artisan Moderation Body (NAMB) for assessment at various steps of applying to be an artisan. If a candidate is unable to supply all the evidence required, he/she will be supported by the RPL advisor to engage in an intervention to fill any training gaps that may exist. Once the gaps in the portfolio of evidence were closed, the RPL candidate, assisted by the RPL advisor applies for admission to the National Trade Testing processes (DHET 2012, 7).

\section{PURPOSE}

This research was conducted in an effort to address the shortage of artisans as highlighted by the South African government. A judgement decision to focus on the motor mechanic artisan trade as a point of departure was made. The underlying reasons for this decision included the fact that the automotive industry in South Africa is well established, with representatives from organised labour, government, automotive associations, professional bodies and academia with public and private training centres (Jordaan 2014). In addition, motor mechanic artisan trade problems and constraints faced in the formal sector may also be applicable to other categories of artisans. One such problem, according to Nzimande (2010), is that there is no coordinated approach to monitoring and reporting between the Further Education and Training (FET) College Sector and the SETA system. Researching the integration of the informal and formal sectors required an asserted effort backed by an analysis-driven research study focused on the key restrains and obstacles faced by experts in the training of artisans especially those in the informal sector of South Africa (Rasool 2010, 9). According to Minister Nzimande (2012, 24), “To a large extent, institutional and general public knowledge of this process has been lost to South Africa. The conflated and confusing sector-based skills development system has created huge blockages to a simple and easy-to-understand artisan development, system.”

\section{METHODOLOGY}

This study was exploratory in nature and a qualitative design outlined in a phenomenology was used. Individuals who represented the academia, public and private FET colleges, MerSETA, major automotive industries and organised labour were targeted utilising a purposive and snowball sampling to select sixteen $(\mathrm{N}=16)$ people to participate in the research (Saunders, 
Lewis and Thornhill 2009, 139). Considerations such as access to the target population and their industry experience supported the sampling techniques chosen. Senior individuals, who were either managers or heads of the respective motor industry training divisions, who had more than five years' experience in the training of motor mechanics field were considered for inclusion in the sample population.

The researcher used semi-structured interviews to collect data from expert participants who met the said criteria (Reiter, Steward and Bruce 2011, 41; De Vos 2004, 302). The semistructured interview allows for probing of views and opinions where it is desirable for participants to expand their answers (Gray 2009, 173; Smith and Osborn 2008, 57). The researcher prepared an interview guide beforehand based on the literature review for the research. Spradley $(1979,46)$ suggests that various types of interviewing questions be used during the interview. In this study, a descriptive question was posed: What factors/constraints do you think contribute to the shortages of artisan skills in general? A structural question: What interventions could be included in a strategy to link the formal and informal sectors of the artisan communities in South Africa? A contrast question: How does South Africa compare with other developing countries regarding artisan training? Lastly, an evaluative question: Could the national skills master inventory list be amended to include artisans operating in the informal sector? In addition, Rubin and Rubin (2005, 135) mention the including of investigative research questions will ensure that the research problem be thoroughly examined and that each part of the broad topic be explored. Collection was discontinued when data saturation had been reached (Maree 2007, 79; Polit and Beck 2008, 521; Streubert-Speziale and Carpenter 2003, 174).

The formation of content to be analysed was defined and categorised utilising the ATLAS.ti (Version 7.0) Program. The purpose of content analysis is to provide knowledge, new insights, a representation of facts and a practical guide of the data collected with the aim to attain an abbreviated and comprehensive description of the phenomenon. According to (Elo and Kyngäs, 2007, 108), the outcome of the analysis is concepts or categories describing the phenomenon. The researcher attempted to maintain the trustworthiness of the research by applying various reasoning strategies, such as content analysis, inductive reasoning, blending, bracketing and understanding in order to interpret the data (Kvale 1996, 160). According to Mey (2010, 72), the researcher endeavours to describe with words the experiences of the participants relating to the investigation of the phenomenon by bracketing out any possible prejudiced ideas about the phenomenon under discussion. Bracketing is the cognitive process of withstanding one's own beliefs, not creating conclusions about what was perceived, and 
remaining open to data collection and analysis (Arjun 2011, 63; Van Manen 1997, 175).

An audio recorder was used to accurately collect raw data from the interviews. To avoid any misinterpretation of the data, the researcher made his own field notes throughout the interviews, which were later compared with the digital recordings after they had been transcribed.

\section{FINDINGS}

A focused RPL process model was developed to identify specific points where the RPL assessment could be applied to facilitate entry into the formal sector training process to link the learning in the two motor mechanic sectors. The linkage would be possible through the compilation of a portfolio of evidence aimed at assisting the informal motor mechanic artisan to obtain either a full qualification or, alternatively, to master specific modules of employability skills. Figure 1 below represents an overview of the proposed focused RPL process model that emanated from the participants' descriptions on how to integrate the two sectors.

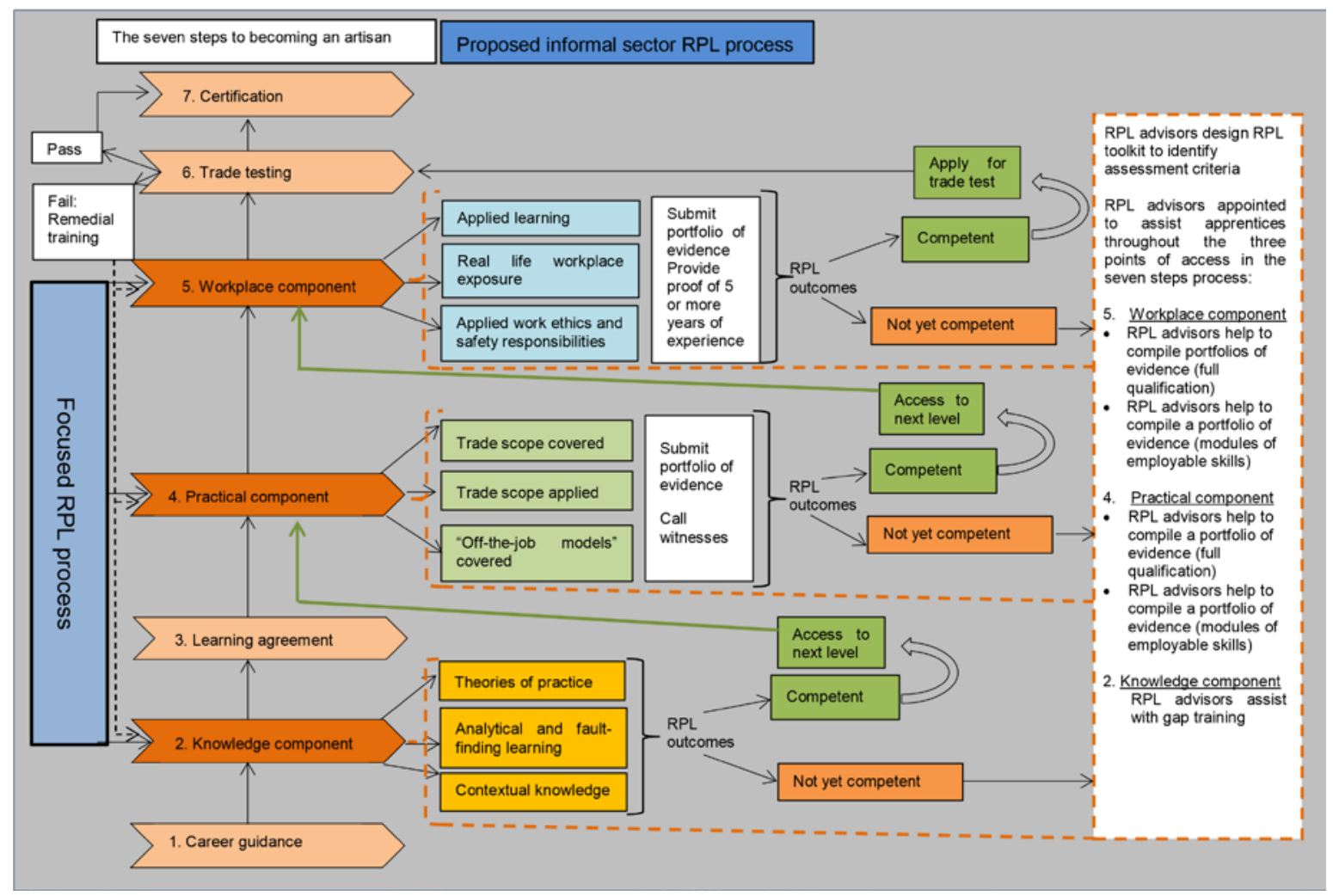

Figure 1: A proposed RPL process model to link informal and formal artisan training (Source: Jordaan 2014)

Figure 1, depicts an RPL process model specifically designed for the motor mechanic trade and 
focuses on three distinct steps as points of access into the seven-step process to become a qualified artisan. The first access would be at step 2: the knowledge component; the second access step is at the practical skills component (step 4); and the last is at step 5: the workplace component. In contrast, step 1: career guidance, would not be applicable because the informal practising artisan is already practising the trade and should be familiar with its demands. In addition, step 3: the learning agreement, would not be applicable because the artisan is either informally employed or is working as an entrepreneur. Step 6: trade testing, is the second last step in the seven-step process that can only be accessed once all the previous steps' criteria have been met. This is also the most important point in the qualification award process (Indlela 2012, 8).

Each of the above listed access points of entry (the knowledge, practical skills and workplace components) will now be individually described in the order in which they appear in Figure 1.

\section{Point of access: Step 2, the knowledge component}

The knowledge component consists of three distinct theories, namely a theory of practice, an analytical and fault-finding learning theory and a contextual knowledge component applicable to the motor mechanic trade. It is compulsory for an apprentice to have mastered all three of these theory components before progressing to the next step of the seven-step process to becoming an artisan. The process model proposed that the following actions be followed regarding the knowledge component:

- The informal practising artisan applies for an RPL assessment to determine what his/her competency levels are as per requirements set for the knowledge component for the motor mechanic trade.

- If the applicant is found to be competent in all three theories, he/she may progress to the practical skills component level four.

- When the applicant is found to be not yet competent, an RPL advisor is appointed to assist with gap training in either one or all three theories for motor mechanics, be it the trade-, analytical and fault-finding theory and or the related knowledge component. Specific remedial training should be identified which need to be addressed by the RPL advisor.

- When the RPL advisor is satisfied that the gaps have been filled, the applicant may again apply for the RPL assessment at the same level that the previous RPL was requested. A New updated portfolio of evidence needs to be compiled to serve as evidence that the 
identified gaps are closed through specific training interventions.

\section{Point of access: Step 4, the practical component}

The practical skills component consists of two separate components, namely: 1) the trade curriculum (proving that the curriculum can be applied in practice); 2) proving that the "offthe-job modules” of training mastered. From the results, the researcher drafted the proposed process for the practical component as follows:

- $\quad$ The informal practising artisan applies for the RPL assessment submitting a portfolio of evidence proving the mastering and application of the trade curriculum as well as that the “off-the-job modules” of training were learnt.

- If the portfolio proves that the criteria for the practical component were met, the person may progress to the practical workplace level of the seven-step process.

- When the portfolio lacks evidence, an RPL advisor is to assist the candidate to compile a portfolio to fill the gaps identified and to construct evidence that meets the criteria determined for the practical component.

\section{Point of access: Step 5, the workplace component}

The workplace component represents the following four separate criteria: 1) applied learning; 2) proof of real-life workplace exposure; 3) proof that the workplace ethics and 4) safety responsibilities were applied. In addition, the workplace component can be divided into the following two categories: a complete component or a component referred to as modules of employability skills. The process model depicts the workplace component be as follows:

- The informal practising motor mechanic applies for the RPL assessment either for a full qualification or for a module of employability skills.

- $\quad$ The candidate submits a portfolio of evidence to be assessed, proving that the criteria for the workplace component have been met.

- The candidate must provide evidence that he/she has been practising the trade for more than five years. He/she may call witnesses to confirm the number of years.

- $\quad$ The RPL advisor submits the portfolio of evidence for assessment by an independent assessor.

- When the portfolio has been assessed and the outcome is positive, the applicant may apply for a trade test, either for a full qualification or a module of employability skills. 
- If the portfolio lacks evidence, the candidate, together with the RPL advisor, identifies the areas of concern and starts to build a new portfolio and to fill the knowledge/ practical/workplace component gaps through remedial training.

\section{ETHICAL CONSIDERATIONS}

For this study, the researcher informed the participants in advance of the nature of the research and that any data collected would not be linked back to them. The researcher followed Leedy and Ormrod's $(2013,151)$ suggestion to keep the data confidential by allocating various pseudonyms to different participants and using aliases both during data collection and in the final research report. For example, the participants were referred to as P1, P2 and P3, meaning participant 1, 2 and 3, and so forth.

Participants were asked to sign an informed consent form which was designed to include a summary of the ethical issues (Joubert 2012, 14; Mey 2010, 93). They were reminded throughout the study that their participation was completely voluntary (Strydom 2012, 118). The research report does not refer to any specific person or institution.

\section{DISCUSSION}

The objective of this study was to develop a process model to establish how large numbers of informal practising motor mechanics could be linked to the formal sector training processes. The results indicated that the sector linkage could be done through a focused RPL process model and formal gap training, as referenced in the interviews. "it should be through a focused recognition of prior learning (RPL) system that includes gap training” (P1, P2, P6, P7, P9, P10 and P14).

Gap training refers to the acquiring of knowledge, practical skills or workplace experience which focuses on the requirements of the scope of a trade to gain access to a trade test. In the motor mechanic artisan trade, gap training will follow after the assessment of the portfolio of evidence. The differences between the required skills needed to perform a task satisfactorily and the existing skill levels will indicate the areas for improvement. Specific training interventions are normally commended for decreasing the differences and/or closing the skills gap.

The issue of having the current motor mechanic curriculum fragmented to provide for modules of employability skills was also highlighted: "the models of employable skills should be considered with the RPL process and the linkage of the sectors” (P8, P9, P10 and P14).

Modules of employability skills entail the application of a group of essential abilities 
(knowledge skills and practice) that can be utilised by industry to support service delivery, combined they make up a trade occupation: “The ‘trade qualification' must have clear unit standards (modules) that are packaged into employable skills units meaning that the individual who has achieved that unit or combination of unit standards will be employable and can be selfemployed” (P7, P8, P12, P14 and P15). In the motor mechanic artisan trade, it would be the fragmentation of the trade to allow a person to become competent in one or multiple modules of employability of the trade, for example, to only work on engines, gearboxes or autoelectronics, and so forth (Jordaan 2014).

\section{PRACTICAL IMPLICATIONS}

A focused RPL process model that is specifically designed for the motor mechanic trade will focus on three distinct steps as points of access to the seven-step process to becoming an artisan, namely step 2: the knowledge component; step 4: the practical skills component; and step 5: the workplace component. One should note that the first point of access would be at step 2, the knowledge component. The applicant needs to demonstrate competencies in three distinct theories, namely a theory of practice, an analytical and fault-finding learning theory and a contextual knowledge component. The second point of access is at step 4, the practical component, where the applicant has to prove mastery of the trade scope (curriculum); proving that the curriculum was mastered through learning and can be applied in practice; and proving that the "off-the-job modules" of training were mastered. The last point of access is at step 5, the workplace component, which represents four separate criteria: applied learning; proof of real-life workplace exposure; and proof that both workplace ethics and safety responsibilities were applied.

\section{LIMITATIONS AND RECOMMENDATIONS}

This study was conducted in the motor industry, the data collected stemmed from the personal experiences of industry experts involved in the training of motor mechanic artisans. Hence the findings cannot be generalised to other artisan trades. The participants in this study agreed that the recognition of prior learning for the motor mechanic trade is a possibility, provided that the following prerequisites are met:

- The inclusion of the informal sector should be done by means of a focused RPL process and a formal gap training programme should be in place.

- The learning acquired in the informal sector should be acknowledged and the formal sector 
should make an effort to provide some gap training.

- Consensus was reached that the informal practising artisan would benefit from the integrated sectors and would have enhanced employment opportunities whether these be full qualifications or modules of employability skills.

\section{CONCLUSION}

The findings indicated that the two sectors could be linked through dedicated recognition of the prior learning system backed by a process of gap training. The findings also highlighted the importance of having modules of employability skills to enhance informal practising artisans' employability status. Finally, this study recognised particular limitations that contribute to the shortage of skilled motor mechanics in general. This research confirmed that a strategy could be developed to successfully link informal and formal motor mechanic artisan training, through focused training opportunities resulting in a successful RPL process.

\section{ACKNOWLEDGEMENTS}

A word of gratitude to the different automobile industries for their participation in the study as well as to TUT, who granted the researcher sabbatical leave and financial assistance to execute this research.

\section{SUGGESTIONS FOR FUTURE RESEARCH}

The following are recommendations for potential future research:

- $\quad$ A study could be conducted to design a funding model, which would include the informal sector, to fund the motor mechanic artisan trade.

- $\quad$ The actual implementation of this empirical study could be researched.

- An empirical study could be conducted to determine the actual training needs of the informal practising motor mechanic artisan.

\section{REFERENCES}

Arjun, S. D. 2011. The experiences of enrolled nurses caring for multi-drug resistant tuberculosis patients in Kwazulu-Natal. MA. dissertation, University of South Africa.

Akoojee, S. 2011. National context of apprenticeship training in South Africa: Possibilities and challenges in a new structural order. Proceedings of a conference organised by the International Network on Innovative Apprenticeship, Beijing, China, 26-27 May.

AMA see Amalgamated Motor Holdings.

Amalgamated Motor Holdings. 2012. Letter to Minister Patel.

Andersson, P., A. Fefes and S. Ahn. 2004. Recognition of prior vocational learning in Sweden. Studies in the Education of Adults, 36(1). http://web.ebscohost.com/ehost/detail?vid=4\&hid=12\&sid= 
3818338f-c156-454a-a0fb-d5 (Accessed 7 May 2011).

Bolton, H. 2011. RPL as a key factor within a skills development context and post school system. In National Skills Authority, First National Skills Development Conference, October. Conference Report. DHET.

Botha, L., J. Kiley, K. Truman and M. C. Tshilongamulenzhe. 2012. Training and development in the South African context. In Practising education, training and development in South African organisations, ed. M. Coetzee. Cape Town: Juta.

Bowers, N., A. Sonnet and L. Bardone. 1999. Giving young people a good start: The experience of OECD countries. In OECD, Preparing youth for the twenty-first century: the transition from education to the labour market, 7-84. Paris.

Bowman, K., B. Clayton, A. Bateman, B. Knight, P. Thompson, J. Hargreaves, K. Blom and M. Enders. 2003. Recognition of prior learning in the vocation education and training sector. Adelaide, South Australia: NCVER.

Breier, M. 2009. The RPL conundrum: Recognition of prior learning in a teacher upgrading programme. Cape Town: HSRC Press.

Castle, J. and G. Attwood. 2001. Recognition of prior learning (RPL) for access or credit? Problematic issues in a university adult education department in South Africa. Studies in the Education of Adults 33(1). http://web.ebscohost.com/host/detail?vid=4\&hid=112\&sid=3f6d34c3-95a0-4a39b56b-6 (Accessed 4 May 2011).

Connellan, G. 2011. Association for skills development facilitation in South Africa. http://www.skillsuniverse.com/photo/gill-connellan (Accessed 20 June 2011).

De Vos, A. S. 2004. Research at grass roots. Pretoria: Van Schaik.

Department of Higher Education and Training. 2012. National Artisan Development RPL model framework for support workers in the engineering field (artisan aides, maintenance operators, artisan assistants etc.). Version 4. 16 November 2011. Pretoria: DHET.

Department of Higher Education and Training. 2013. National Artisan Development Funding and Learner Administration Policy. Pretoria: DHET.

DHET, see Department of Higher Education and Training.

Elo, S. and H. Kyngäs. 2007. Research methodology: The qualitative content analysis process. Journal of Advanced Nursing 14(1): 1-37.

Esterhuisen, J. 2012 President of the Retail Motor Industry. Personal communication.

Gray, D. E. 2009. Doing research in the real world. $2^{\text {nd }}$ Editionnd. London: Sage.

Hamill, J. and J. Sutherland. 1994. Accrediting prior learning. Reader in Labour Market Studies, Leeds Business School 36(4). http://www.emeraldinsight.com/Insight/ViewContentServent?Filename =Published/Emerald (Accessed 9 May 2011).

IMI, see Institute of the Motor Industry.

Indlela. 2012. National artisan development and assessment incorporating NAMB. Pretoria: DHET.

Institute of the Motor Industry. 2012. Preparing for the future: Understanding the skills and training needs of the automotive retail sector: Repair and maintenance of light motor vehicles. IMI Research Department. Hertfordshire. http://www.theimi.org.uk/sites/default/files/201206research-report-Repair-light-motor-vehicles.pdf (Accessed 09/08/2012).

Jordaan, C. J. 2014. A strategy to link the informal and formal motor mechanic artisan training in South Africa. DTech thesis. Tshwane University of Technology, Pretoria.

Joubert, Y. T. 2012. Towards an organisational team sport intervention model for managing a diverse workforce. DCom thesis. University of South Africa, Pretoria.

Kvale, S. 1996. Interviews: An introduction to qualitative research interviewing. London: Sage.

Leedy, P. and J. Ormrod. 2013. Practical research: Planning and design. 10th ed. Boston: Pearson Education International. 
Maree, K. 2007. First steps in research. Pretoria: Van Schaik.

Mey, M. S. 2010. The unconscious at work in a historically black university: The (k)not of relationship between students, lecturers and management. DLitt et Phil thesis. University of South Africa, Pretoria.

MerSETA. 2013. Strengthening leadership in closing the skills gap: An overview of MerSETA researchin-action. Johannesburg: MerSETA.

Nzimande, B. E. 2010. Roundtable discussion on the artisanal training programme and the launch of the National Artisan Moderation Body or the NAMB. http://www.info.gov.za/speech/Dynamic Action?pageid=461\&sid=14937\&tid=25154 (Accessed 27 March 2012).

Nzimande, B. E. 2012. Achieve leaders in closing the skills gap. DHET. Drumming up support for artisan development, ed. S. Ziinjiva Ka-Mnguni, 17. September. MerSETA.

Polit, D. F. and C. T. Beck. 2008. Nursing research: Generating and assessing evidence for nursing practice. Philadelphia, PA: Lippincott Williams \& Wilkins.

Prinsloo, F. 2011. Technical advisor national artisan moderation body. Department of Higher Education and Training. Personal communication.

Rasool, H. 2010. Creating a National Skills Development Strategy (NSDS) that works: Learning lessons from mistakes of NSDS I and II. National Skills Planning and Development Series. Durban: Mancosa.

Rasool, F. and C. J. Botha. 2011. The nature, extent and effect of skills shortages on skills migration in South Africa. SA Journal of Human Resource Management/SA Tydskrif vir Menslikehulpbronbestuur 9(1) Art. \#287: 1-12.

Reiter, S., G. Steward and C. Bruce. 2011. A strategy for delayed research method selection: Deciding between grounded theory and phenomenology. Brisbane, Australia: Queensland University of Technology.

Rubin, H. J. and I. S. Rubin. 2005. Qualitative interviewing: The art of hearing data. London: Sage.

Saunders, M., P. Lewis and A. Thornhill. 2009. Research methods for business students. $5^{\text {th }}$ Edition. London: Prentice-Hall.

Smith, J. A. and M. Osborn. 2008. Qualitative psychology: A practical guide to research methods. $2^{\text {nd }}$ Edition. London: Sage.

Spradley, J. 1979. The ethnographic interview. $1^{\text {st }}$ Edition. Wadsworth. http://jan.ucc.nau.edu/ pms/ cj355/readings/spradley.pdf (Accessed 19 August 2013).

Streubert-Speziale, H. J. and D. R. Carpenter. 2003. Qualitative research in nursing: Advancing the humanistic imperative. $3^{\text {rd }}$ Edition. New York: Lippincott.

Strydom, S. C. 2012. A qualitative investigation into the sources of job satisfaction among black middle level managers. D.Litt thesis. University of South Africa, Pretoria.

Stuart, M. 2010. The national skills development handbook 2010/11. Johannesburg: RainbowSa.

Van Manen, M. 1997. Researching lived experience: Human science for an action sensitive pedagogy. London: Althouse Press. 